\title{
CORRIGENDUM
}

\section{Dynamic assessment of antiangiogenic therapy by monitoring both tumoral vascularization and tissue degeneration}

\author{
C Magnon ${ }^{1,8}$, A Galaup ${ }^{2,3,8}$, V Rouffiac ${ }^{4}$, P Opolon ${ }^{1}$, E Connault ${ }^{1}$, M Rosé ${ }^{5}$, M Perricaudet ${ }^{1}$, A Roche R $^{4,6}$, \\ S Germain ${ }^{2,3,7}$, F Griscelli ${ }^{1}$ and N Lassau ${ }^{4,6}$ \\ ${ }^{1}$ UMR 8121 Vectorologie et transfert de génes, Institut Gustave Roussy, Villejuif cedex, France; ${ }^{2}$ INSERM U36 Pathologie vasculaire \\ et endocrinologie rénale, Paris, France; ${ }^{3}$ Chaire de Médecine Expérimentale, Collége de France, Paris, France; ${ }^{4}$ Laboratoire d'imagerie \\ dupetit animal (LIPA), Institut Gustave Roussy, Villejuif cedex, France; ${ }^{5}$ Département de statistiques, Institut Gustave Roussy, Villejuif \\ cedex, France; ${ }^{6}$ Département d'imagerie médicale, Institut Gustave Roussy, Villejuif cedex, France and ${ }^{7}$ Service d'Hématologie Biologique \\ A,AP-HP Hôpital Européen Georges Pompidou, Paris, France
}

Gene Therapy (2007) 14, 190. doi:10.1038/sj.gt.3302901

Correction to: Gene Therapy (2007) 14, 108-117. In the original publication, the affiliations linked to doi:10.1038/sj.gt.3302849

$\mathrm{N}$ Lassau were published incorrectly. The correct linked affiliations are given above. 